\title{
Pulmonary circulation and ventilation
}

\author{
Julian M. LEIGH \\ M.D., F.F.A.R.C.S. \\ Magill Department of Anaesthetics, Westminster Hospital, London
}

\begin{abstract}
Summary
The pulmonary circuit receives the whole of the cardiac output, and the flow through it is governed by events in the systemic circulation. Its function is gaseous exchange, and the low resistance and high capacitance of the circuit is subservient to this function. Local flow is affected by intra-alveolar oxygen tension, and regional flow by passive hydrostatic effects due to gravity. The distribution of ventilation is also affected by gravity owing to the effect of the latter on regional compliance. When the cardiac output falls, as it does in most methods of induced hypotension, there is an accompanying increase in physiological dead space owing to an increase in the alveolar component.
\end{abstract}

IN 1616 William Harvey posed three basic questions, the answers to which were eventually to materially advance cardio-respiratory physiology. These were:

(1) Do the lungs have any special function at all?

(2) If so, is it of the nature of alteration, or heating or cooling? If it be heating, does the heating involve preparation or concoction?

(3) What is the basis of this alteration and what does it do with each of blood, air and spirit?

Twelve years later in 1628 he published his famous 'De Motu Cordis' in which he correctly described the circulation of the blood. However, he was still unaware of the existence of capillaries, although they were of course essential to his theory. He thought that the circulation of blood through the lungs was with the object of mixing the red portion with the serum evidenced by the resulting colour change.

In 1661 Marcello Malpighi, using the light microscope, identified both the capillaries and alveoli, and in 1669, Richard Lower wrote his 'Tractatus de Corde' in which he correctly described the way in which venous blood is arterialized in traversing the lungs, and demonstrated that the act of ventilation was essential to this function. In addition, he knew from the work of Boyle, Hooke and Mayow that the absorption of a vital chemical from the air was also involved.

Virtually 200 years later Adolph Fick (1870) at a meeting of the Physico-Medical Society of Wurzburg theorized on some early measurements of blood gas contents in dogs and oxygen consumption in man. He calculated that the pulmonary blood flow was $4.9 \mathrm{l} / \mathrm{min}$. Knowing that the pulmonary blood flow constitutes the whole cardiac output, he determined that the stroke volume of the heart was $77 \mathrm{ml} /$ beat.

The function of the pulmonary circulation is the exchange of the respiratory gases according to the tension gradients from the blood to the alveoli or vice versa. In this way 3601 of oxygen are exchanged for 2881 of carbon dioxide in a single day. The gas exchange surface, the alveolar/capillary membrane, is distributed among 350 million alveoli. Together they constitute an area of $70 \mathrm{~m}^{2}$ (40 times the body surface area). The blood flows as if in a sheet over this large area and since the capillaries are approximately $4 \mu$ in diameter, that is the thickness of the sheet of blood. It is another remarkable fact that the capillary blood volume of $60-100 \mathrm{ml}$, is renewed approximately every half second. The lungs thus constitute a remarkably efficient gas exchanging system.

The pulmonary circulation is unique in that it must carry the entire cardiac output. The cardiac output is regulated by the venous return volume which is in turn regulated by the demands of the systemic organs. The pulmonary circuit must therefore play a passive role and be capable of coping with flows which vary from $3 \mathrm{l} / \mathrm{min}$ during sleep to $25 \mathrm{l} / \mathrm{min}$ or more during exercise. In the lungs capillary blood is exposed via the alveolar/capillary membrane to intra-alveolar pressure which is low, and the only force preventing the capillary blood pressure from pushing fluid into the alveoli is the colloid osmotic pressure. It is therefore essential that the colloid osmotic pressure is never exceeded by the intra-capillary blood pressure. The pulmonary circuit thus has a low resistance and high capacitance to preserve this relationship. This is achieved under conditions of high flow by the distensibility of the large blood vessels, by expansion of already open capillaries, and by recruitment of hitherto unopened capillaries.

It is a low resistance and therefore a low pressure system, the resistance being one-tenth of that in the 
systemic circulation and the systolic pressure approximately one-sixth, i.e. $20 \mathrm{mmHg}$ as opposed to 120 $\mathrm{mmHg}$. The mean capillary pressure is over $20 \mathrm{mmHg}$ in the systemic circulation, and in the region of $10 \mathrm{mmHg}$ in the pulmonary circulation. The low resistance and low pressure means that the right ventricle has to do less work and is consequently only one-third of the thickness of the left ventricle. Similarly, the main pulmonary artery is only twice as thick as the vena cava and one-third of the thickness of the aorta.

\section{Distribution characteristics of the pulmonary blood flow}

The Important distributional characteristics are:

(1) Alteration of flow at alveolar level by the alveolar oxygen tension.

(2) The passive hydrostatic effects of gravity on flow distribution.

\section{Oxygen}

The response of muscular pulmonary vessels to alveolar hypoxia is to constrict. At the local level this redistributes blood to better aerated regions but if it is generalized, as it is in inhabitants of high altitude, pulmonary hypertension and right ventricular hypertrophy will ensue.

The mechanism is dependent upon the fact that alveolar gas not only penetrates through capillary walls but also through vessels of up to $3 \mathrm{~mm}$ in diameter (Sobol et al., 1963). Since vessels of this diameter are equipped with muscle, it can be seen that they are able to redistribute blood if there is intra-alveolar hypoxia. This response by pulmonary vessels is in contradistinction to the response of systemic vessels to hypoxia. In systemic vessels there is a direct relationship between oxygen availability and the contractile strength of the systemic vascular smooth muscle. This is best seen in the ductus arteriosus in which tonic contraction in the face of an increased oxygen tension is an essential feature of the transition from foetal to neonatal existence. During exercise, for example, hypoxia in active vascular beds causes dilatation of distributing vessels to increase the blood supply to the active region.

The hypoxic pulmonary pressor response must involve a local humoral mechanism since isolated strips of pulmonary artery have the opposite response to oxygen than in vivo (Lloyd, 1967), i.e. the strips respond like systemic vascular smooth muscle. The mechanism probably involves the release of noradrenaline and/or histamine.

\section{Gravity}

Since the pulmonary circuit is a low pressure system it is subject to the hydrostatic effects of gravity. Figure 1 (West, Dollery and Naimark, 1964) shows how the upright lung may be divided into three zones by the pulmonary artery pressure (shown on the manometer on the left of the lung) and the pulmonary vein pressure (shown by the height of the manometer on the right of the lung). Gravity does not affect intra-alveolar pressure because of the very much lower density of air. In the upper zone (Zone 1) intra-alveolar pressure is higher than both arterial and venous and therefore no flow occurs. In Zone 2 the arterial pressure exceeds intra-alveolar pressure and therefore flow increases down this zone and is governed by the arterial to alveolar pressure gradient. In Zone 3 venous pressure now exceeds intra-alveolar pressure and therefore flow, which increases down this zone, is governed by the gradient between arterial and venous pressure. There is, in addition, a fourth zone at the bottom of the lung in which interstitial pressure is sufficiently high to cause a reduction in flow, but this zone is not material to the discussions in the present context.

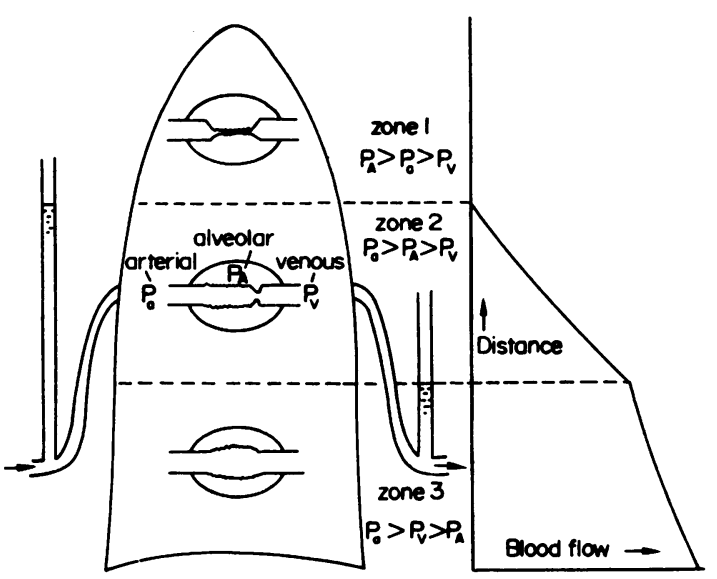

Fig. 1. Model of the distribution of pulmonary perfusion by reason of the relative alveolar, arterial and venous pressures. For full description see text. (From West et al., 1964, by permission of the editors, Journal of Applied Physiology.)

The distribution of ventilation is also influenced by the effects of gravity on the compliance of the different parts of the lung. The compliance is greater at the bottom, so that ventilation is better at the bottom of the lung than at the top. In Fig. 2 (West, 1963) an experiment is shown in which the distribution of both ventilation and perfusion is elegantly demonstrated. The subject is seated and two scintillation counters scan the upper and lower portions of the lung. The subject breathes out and the next inspiration has added to it $\mathbf{C}^{15}$-labelled carbon dioxide. During inspiration the two traces show that the amplitude is higher at the bottom than the top 


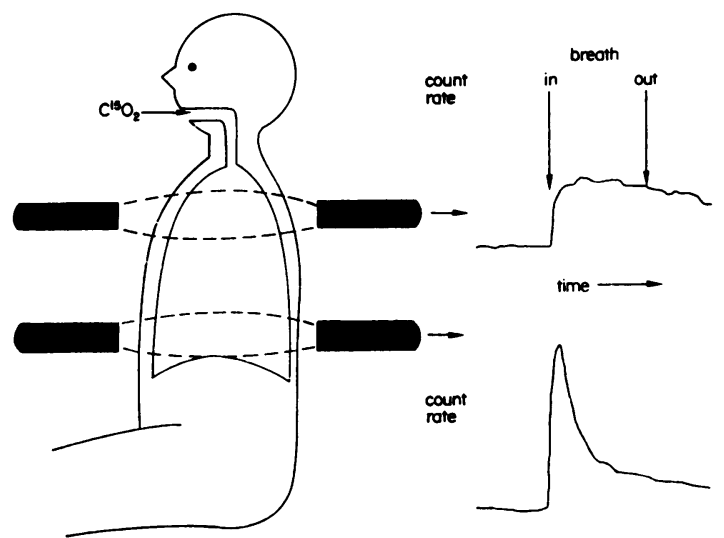

FIG. 2. The distribution of ventilation and perfusion in the upright human lung as determined by the inhalation of $\mathbf{C}^{\mathbf{1 5}}$-labelled carbon dioxide. For further description see text. (From West, 1963, by permission of the editors, British Medical Bulletin.)

of the lung, i.e. ventilation is greatest at the bottom. During the breath-holding interval the washout from the bottom of the lung is much greater than that at the top, i.e. perfusion is much greater at the bottom than at the top of the lung. The ventilation/ perfusion ratio which results is greater at the top than at the bottom of the lung.

\section{Matching between ventilation and perfusion}

Figure 3 (Leigh, 1970) shows a model which explains the possible relationships (matching) which can exist between ventilation and perfusion. The model permits of there being two kinds of alveoli, open like the two on the right and closed like the one on the left (CA), and two kinds of capillary, open like the two on the left and closed like the one on the right (CPC). The capillary which is perfused but not going to an aveolus which is ventilated causes shunt or venous admixture (Qs). The capillary which is open and also in contact with an open ideal alveolus (VA) constitutes the ideal pulmonary perfusion $(\mathrm{Qc})$ with a result that the blood is in equilibrium with ideal alveolar gas. The relationship shown on the right, i.e. an open alveolus which is ventilated but in contact with a closed pulmonary capillary, constitutes alveolar dead space (VD ALV) and it is this type of relationship which is of interest to us in induced hypotension. The obligatorily wasted ventilation of the conducting airways constitutes the anatomical dead space (VD ANAT). The alveolar dead space plus the anatomical dead space together constitute total physiological dead space. The total ventilation is VE and the total pulmonary perfusion is Qt.

During induced hypotension by ganglionic blockade, by halothane or by haemorrhage, the hypoten-

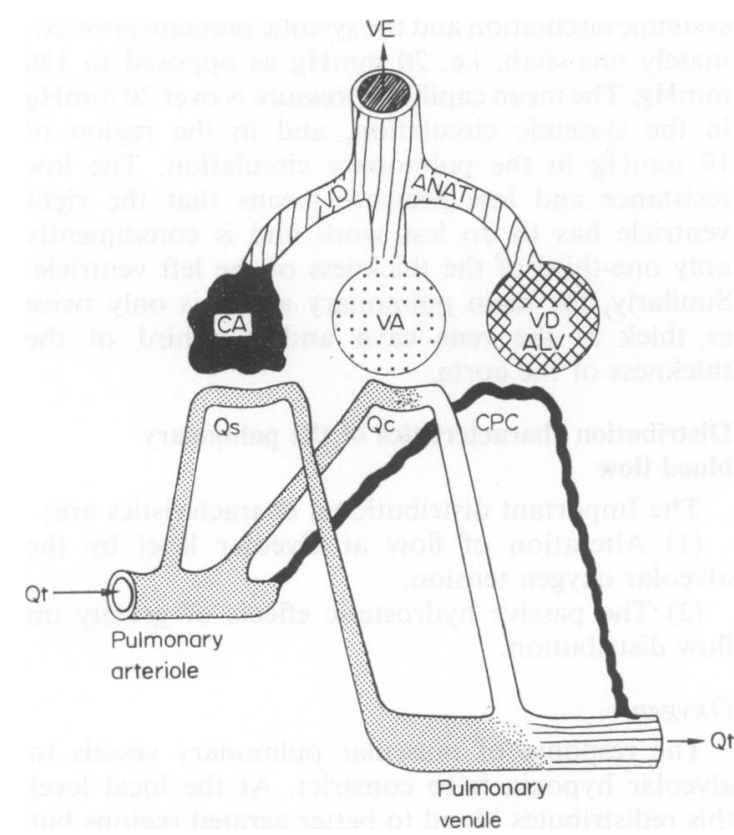

FIG. 3. Model of the matching between ventilation and perfusion. For full description see text. (From Leigh, 1970 , by permission of Heinemann Medical Books.)

sion is associated with a reduction in cardiac output and therefore pulmonary blood flow. The effect of this is that during the hypotension less pulmonary capillaries are perfused and this is manifest as an increase in alveolar and physiological dead space. Eckenhoff et al. (1963) showed that, in man in the $30^{\circ}$ head up posture, induced hypotension could be associated with total physiological dead spaces of up to $80 \%$. Leigh and Tyrrell (1969) demonstrated dead spaces of the same order during hypotension by either ganglionic blockade, deep halothane or haemorrhage in three groups of dogs. The accompanying falls in mean pulmonary artery pressure were very small, of the order of $3 \mathrm{mmHg}$, reflecting the low resistance of the system. Under clinical circumstances in man the change in alveolar dead space can be followed by monitoring tidal carbon dioxide percentage in the respired gas. Under these circumstances it can be demonstrated that the endtidal carbon dioxide level changes in harmony with changes in the systemic arterial pressure, thus reflecting the accompanying changes in cardiac output and the accompanying alterations in pulmonary capillary perfusion.

\section{References}

Eckenoff, J.E., Enderby, G.E.H., Larson, A., Edridge, A. \& Judevine, D.E. (1963) Pulmonary gas exchange during induced hypotension. British Journal of Anaesthesia, 35, 750 . 
FICK, A. (1870) Uber die Messung des Blutquanturns in den Herzventrikeln. Sitzungsberichte Physikalisch-medizinischen Gesellschaft Würburg, XIV, XVI.

Harvey, W. (1616) Prelectiones Anatomiae Universalis. Quoted by L.G. Wilson (1960). The transformation of ancient concepts of respiration in the seventeenth century. Isis, 51, 161 .

Harvey, W. (1628) Exercitatio de Motu Cordis et Sanguinis in Animalibus. Translated by K.J. Franklin (1957), Springfield, Illinois: Thomas.

Leigh, J.M. (1970) The pulmonary circulation. In: Scientific Foundations of Anaesthesia. London: Heinemann.

Leigh, J.M. \& Tyrrell, M.F. (1969) Some haemodynamic effects of induced hypotension in dogs. In: Progress in Anaesthesiology, Proc. IVth World Congress of Anaesthesiologists (Ed. by T.B. Boulton, R. Bryce Smith, M.K. Sykes, G.B. Gillet and A.L. Revell). Amsterdam: Excerpta Medica Foundation.
Lloyd, T.C. (1967) Influence of $\mathrm{Po}_{2}$ and $\mathrm{pH}$ on resting and active tensions of pulmonary arterial strips. Journal of Applied Physiology, 22, 1101.

Lower, R. (1669) Tractatus De Corde. Translation by K.J. Franklin in R.T. Gunther's Early Science in Oxford (1932), Vol. IX. Oxford University Press: Oxford.

Malpighi, M. (1661) Duae Epistolae de Pulmonibus. Quoted by L.G. Wilson (1960). The transformation of ancient concepts of respiration in the seventeenth century. Isis, $51,161$.

Sobol, B.J., Bottex, G., Emirgil, C. \& Gissen, H. (1963) Gaseous diffusion from alveoli to pulmonary vessels of considerable size. Circulation Research, 13, 71.

WEST, J.B. (1963) Distribution of gas and blood in the normal lungs. British Medical Bulletin, 19, 53.

West, J.B., Dollery, C.T. \& Naimark, A. (1964) Distribution of blood flow in isolated lung: Relation to vascular and alveolar pressures. Journal of Applied Physiology, 19, 713. 